coherency matrix and to a unique set of Stokes parameters. The degree of polarization of such a wave was also equal to the maximum value of the degree of coherence which existed between the components of electric vibrations in orthogonal directions in the wave front. This suggested a new method of measurement of the degree of polarization, based on interference experiments.

Prof. E. G. Richardson (King's College, Newcastle) referred to experiments on the propagation of sound waves in a fluid having random variations in either density or momentum, whereby the amplitude and relative phase of the signal picked up after transmission through the medium fluctuated in time. The former type occurred near the critical point of a fluid or of a mixture of liquids, the latter in the atmosphere or in the wake of an obstacle or, again, in a boundary layer. Analyses of such measurements were presented. In the case of the liquid mixture a correlation was sought between the pattern of the scattered radiation and the mean size of the clusters which formed at the critical point. As an example of the second type, frequency spectra of the modulations of the sound signal transmitted athwart the wake of a cylinder involved the discerning of peaks in the spectrum against the background of fluctuation 'noise' in the general flow.

Dr. M. S. Longuet-Higgins (National Institute of Oceanography) discussed "Sea-Waves as a Stochastic Process". He showed a typical record of pressure at a fixed point on the sea bed which agreed elosely with a Gaussian distribution. Non-Gaussian features usually appeared when the waves were steep and near the point of breaking, or in shallow water. To describe the sea surface a random process two spatial dimensions and one of time were needed; the practical problem for wave forecasting was to relate this to winds and other relevant factors. Dr. Longuet-Higgins also listed a number of properties of a Gaussian surface which might be of use in determining the spectrum; these included wave slopes ${ }^{19}$, 'specular points' and 'twinkles'20.

The final paper was given by Prof. E. W. Montroll (University of Maryland) on a stochastic treatment of traffic flow. Experimental data indicated that the acceleration of a car in a line of traffic at time $t$ was proportional to the velocity difference between itself and its neighbour at time $(t-\Delta)$, where $\Delta \sim 1.5$ sec. and the proportionality constant ${ }^{21}$ was 0.37 sec. $^{-1}$. Theoretical investigation showed that the motion became unstable when the product of lag time and proportionality constant exceeded $1 / 2$. Thus the experimental data showed that driving was usually on the verge of instability. 'Acceleration noise' was put forward as a parameter which would characterize the driver - car - road complex under various con. ditions ${ }^{22}$. Reasonable agreement was obtained with traffic flow measurements ${ }^{23}$.

The conference was organized at the suggestion of Dr. Furth, who is to be highly commended on his initiative. The one hundred participants would undoubtedly wish to express their thanks to him, to Birkbeck College, and to the Physical Society for the excellent arrangements.

C. Dомв

${ }^{1}$ Hagfors, T., and Landmark, B., Proc. Inst. Elec. Eng., B, 105, 555 (1958).

'Rice, S. O., Bell Syst. Tech. J., 23, 282 (1944).

${ }^{3}$ Moore, M. N., Nuclear Science and Engineering, 3, 387 (1958).

4 Broadbent, S. R., and Hammersley, J. M., Proc. Camb. Phil. Soc. 53, 629 (1957). Hammersley, J. M., ibid., 53, 642 (1957); Ann. Math. Statist., 28, 790 (1057)

${ }^{5}$ Hammersley, J. M., and Morton, K. W., J. Roy. Stat. Soc., B, 16. 23 (1954).

${ }^{6}$ Fisher, M. E., Farad. Soc. Disc., 25, 200 (1958).

'Wall, F. T., Hiller, L. A., and Atchison, W. F., J. Chem. Phys., 26 1742 (1957). Wall, F. T., Rubin, R. J., and Isaacson, L. M. J. Chem. Phys., 27, 186 (1957).

${ }^{8}$ Fisher, M. E., and Sykes, M. F., Phys. Rev., 114, 45 (1959). ${ }^{8} a$ Green, R., Nature, 182, 382 (1958). "'s Fisher, R. A., Proc. Roy. Soc., A, 217. 295 (1953).

- Barton, J. C., Campbell, D. A., and Read, R. C., Proc. Phys. Soc., A, 70,605 (1957).

${ }^{10}$ Daniels, H. E., Proc. Roy. Soc. Edin., 63, 290 (1952).

$"$ MacDonald, D. K. C., Phys. Rev., 108, 541 (1957).

${ }_{12}$ Davies, R. O., Physica, 24, 1055 (1958).

${ }^{13}$ Van Kampen, N. G., Phys. Rev., 110, 320 (1.958).

${ }^{14}$ Thomson, J. J., Phil. Mag., 47, 337 (1924).

${ }^{15}$ Jaffe, G., Phys. Rev., 58, 968 (1940).

${ }^{16}$ Fejer, J. A., Proc. Roy. Soc., A, 220, 445 (1953). Feinstein, J. Trans. Inst. Rad. Eng., APे-2, 23, 63 (1954). Bramley, E. N.' Proc. Roy. Soc., A, 225, 515 (1954).

${ }^{17}$ Pitteway, M. L. V., Proc. Roy. Soc., A, 246, 556 (1958).

${ }_{18}$ Briggs, B. H., Phillips, G. J., and Shinn, D. H., Proc. Phys. Soc. B, 68, 106 (1950). Phillips, G. J., and Spencer, M., ibid., 68, 481 (1955).

19 Cox, C., and Munk, W., J. Opt. Soc. Amer., 44, 838 (1954).

${ }^{20}$ Longuet-Higgins, M. S., Phil. Trans. Roy. Soc., A, 249, 321 (1957); 250,157 (1957) ; Proc. Camb. Phil. Soc., 55, 91 (1959).

${ }^{21}$ Chandler, R. E., Herman, R., and Montroll, E. W., Operations Res., 6, 165 (1958)

${ }^{2}$ Herman, R., Montroll, E. W., Potts, R. B., and Rothery, R. W. Operations Res., 7,86 (1959).

${ }^{23}$ Greenberg, H., Operations Res., 7, 79 (1959).

\title{
BIOMECHANICS
}

$\mathrm{O}^{\mathrm{N}}$ April 17 the Institution of Mechanical Engineers held a symposium on "Biomechanics" with the purpose of bringing medical men and engineers into closer contact.

Biomechanics, in its broadest sense, may be defined as the branch of science which applies the principles of mechanics and the techniques of engineering to the human body in the process of its repair, and in the field of man-machine relationship, where man is the essential link in operating these machines.

The symposium was opened by the President of the Institution and the papers and discussion were presented under the chairmanship of Prof. S. J. Davies. In the opening paper on the importance of biomechanics as a service to man, illustrated by a discussion of problems in metallic osteosynthesis, J. M. Zarek, from King's College, London, gave a brief account of the nature of biomechanics as a new field of endeavour in which some of the engineering knowledge may be of direct use to the medical man. The man - machine relationship was only mentioned, as this aspect of biomechanics appears to be already well appreciated by the engineers and was not dealt with at the symposium in detail. After discussing the scope of biomechanics, the general history and current British activities in this field were reviewed. Problems of bone repair were considered at length and the work in the Civil Engineering Department at King's College, London, on the stress/bone formation relationship and the behaviour of metals in the human body were diseussed. 
In the second paper, R. I. Tanner, from the Univer. sity of Manchester, presented a paper on some tests on 'Fluon' as a material for artificial animal joints in which results of artificial hip-joint friction and wear are given. They are based on the results obtained by means of simple pendulum apparatus which provides a reasonable approximation to the walking motion of a normal person.

A critical review of published work on the nature of lubrication in animal joints was given by John Charnley from the Department of Orthopædies at Manchester. Further, some of the experiments which have been accepted in support of the theory of hydrodynamic lubrication have been repeated by him to show that the lubrication of animal joints is almost certainly a boundary phenomenon. Charnley emphasized that the coefficient of friction of animal joints reaches a very low figure and surpasses in slipperiness any combination of sliding surfaces known to engineering.

A paper on the provision of workable substitutes for missing or defective limbs was presented by D. S. McKenzie and Brig. N. A. M. Swettenham, from the Limb Fitting Centre, Ministry of Health, Roehampton.

Limb fitting has been essentially a craft until quite recently, and many ideas current in the last century exist materially unchanged to-day. This situation is now changing as a great deal of research work on artificial limbs with emphasis on fundamental studies is in progress. Some of the problems here are very complex. The prosthesis has to replace a human component but it does not necessarily follow that its mechanical design should copy that of the part it replaces. Amputation often changes the pattern of muscular control and weight bearing. The paper also described some of the features governing the construction of artificial limbs. Each case has to be treated individually and ad hoc modifications have to be made to suit individual needs. In a research field of this nature it is difficult to prove that a proposed change has merit, and evaluation techniques still require much development. Some devices evoke general acceptance, but more often individual responses vary and the type of case for which the new idea is best suited must be discovered. Only users can supply the final answer, but they cannot give up unlimited time to experimentation. Objective testing is therefore necessary to eliminate obvious flaws and shorten user trials.
Following the presentation of the papers, a film entitled "Late Results of Four Massive Internal Prosthesis" was shown by A. C. Bingold and W. G. France. Here the authors gave an excellent picture of how, through the co-operation of surgeons with engineers, instead of amputation, limbs can be saved and restored to their normal use.

The success of the symposium, I think, was reflected in the very interesting discussion which followed and well exceeded the time limit allocated for this purpose.

The Institution was honoured by the presence of Sir Harry Platt, of the Royal College of Surgeons, who, in opening the discussion, stressed the importance of interdisciplinary work between the medical men and engineers. He said that the symposium had clearly demonstrated that some of the surgical techniques now in use are so complex that it is impossible for one profession only to solve the problems involved.

Dr. F. C. Harper, of the Building Research Station, showed a film and some results obtained in the course of studying the forces exerted by the human foot in walking, the emphasis there being on the wear resistance of floor surfacing materials.

Dr. J. D. Moreland and Mr. S. J. Thurlow, of the Road Research Laboratory, discussed their investiga. tions into the problems connected with road crash injuries.

Mr. E. H. J. Smyth, an orthopædic surgeon from the Southampton and Isle of Wight Hospital Groups, presented in a very interesting manner his views on the functional significance of the formation of trabeculæ in the neck of the femur.

Finally, because of shortage of time, after a number of speakers discussed a variety of subjects of their own interest, the authors of the papers answered various points raised in the discussion very briefly.

In conclusion, the large attendance and the discussion were an indication that the Institution of Mechanical Engineers had organized a successful symposium which from the 'mixed' audience indicated the growing affinity between engineering and medicine in the process of alleviating human suffering.

The Institution of Mechanical Engineers will shortly publish the proceedings of the symposium, which will include the discussion and communications.

\section{INTERNATIONAL STARCH CONVENTION, 1959}

$\mathrm{T}$ THE ninth annual Starch Convention, which took place at the Cereal Research Station, Detmold, Germany, during April 21-23, was attended by 360 chemists from seventeen nations. The papers which were read to the meeting were divided into four sessions, on research and anolysis, starch manufacture, starch fractions and derivatives and on industrial applications.

The opening address was delivered by T. J. Schoch (Argo, Illinois), whose theme was the application of modern methods of starch chemistry to characterizing its useful properties. Waxy sorghum starch, which is compriser wholly of amylopectin, can be given some of the characteristic properties of corn starch by cross-linking the polysaccharide chains with phosphate, epichlorhydrin or fatty acid groups. The amount of cross-linking agent required to achieve this result is only 1 part per 1,000 parts of starch. Thus waxy starches, which normally give rise to fluid pastes, are deprived of this property and become 'short'. Simultaneously their resistance to shear increases greatly. Another result is that such starches lose the property of gelatinizing in water at a precise temperature, and instead show a gradual increase in solubility with rising temperature. Cross-linking also results in a marked improvement of resistance to freeze-thaw cycles, which has important implications for the food industry. 